\title{
Assessment of impairment in activities of daily living in mild cognitive impairment using an individualized scale
}

\author{
Avaliação do comprometimento nas atividades de vida diária no comprometimento \\ cognitivo leve através de uma escala individualizada
}
Giseli de Fátima dos Santos Chaves, Alexandra Martini Oliveira, Juliana Aparecida dos Santos Chaves, Orestes Vicente Forlenza, Ivan Aprahamian, Paula Villela Nunes

\begin{abstract}
Mild impairment in activities of daily living (ADL) can occur in Mild Cognitive Impairment (MCl), but the nature and extent of these difficulties need to be further explored. The Canadian occupational performance measure (COPM) is one of the few individualized scales designed to identify self-perceived difficulties in ADL. The present study investigated impairments in ADL using the COPM in elderly with MCI. A total of $58 \mathrm{MCl}$ patients were submitted to the COPM for studies of its validity and reliability. The COPM proved a valid and consistent instrument for evaluating ADL in elderly $\mathrm{MCl}$ patients. A total of $74.6 \%$ of the $\mathrm{MCl}$ patients reported difficulties in ADL. Of these problems, $41.2 \%$ involved self-care, $31.4 \%$ productivity and $27.4 \%$ leisure. This data further corroborates recent reports of possible functional impairment in complex ADL in MCl.
\end{abstract}

Keywords: activities of daily living; mild cognitive impairment; occupational therapy; self report.

\section{RESUMO}

A presença de dificuldades leves no desempenho de atividades da vida diária (AVD) pode estar presente no comprometimento cognitivo leve (CCL), mas sua natureza e extensão devem ser melhor exploradas. A medida canadense de desempenho ocupacional (COPM) é uma das poucas escalas individualizadas de autorrelato destinadas a identificar dificuldades no desempenho de AVDs. Este estudo investigou as dificuldades em AVDs através da COPM em idosos com CCL. 58 idosos com CCL foram submetidos à validação da COPM. A COPM se mostrou um instrumento válido e consistente para avaliar desempenho de AVDs em idosos com CCL. 74,6\% dos idosos relatou alguma dificuldade no desempenho de AVDs, sendo 41,2\% em auto-cuidado, 31,4\% na produtividade e de 27,4\% no lazer. Estes dados acrescentam evidências à recente literatura em que afirma que há comprometimento nas AVDs em CCL.

Palavras-chave: atividades cotidianas; comprometimento cognitivo leve; terapia ocupacional; autorrelato.

There is growing evidence that difficulties performing some activities of daily living (ADL) might be present in mild cognitive impairment $(\mathrm{MCI})^{1}$. In 2011, a new classification of MCI was proposed, namely, "MCI due to Alzheimer's disease". The new classification includes the presence of impairments performing complex ADL, but not sufficiently severe to affect functional independence. The previous classification of MCI did not include difficulties performing ADL, only mild cognitive deficits caused by factors other than aging. Moreover, these deficits must be documented by objective testing and MCI patients should exhibit no signs of dementia ${ }^{3}$. Impairments in ADL may be secondary to cognitive problems or to other limitations present in elderly individuals.
The ability to perform meaningful ADL should be one of the therapeutic goals in the care of MCI patients. Instruments that can individually measure and prioritize meaningful ADL for each MCI patient would help in establishing cost-effective interventions. People with MCI have an increased risk of developing Alzheimer (AD) and other dementias ${ }^{4}$ and may be at a pre-dementia stage, a period when curative or preventive interventions are more effective.

The reestablishment of performance despite acquired limitations is a field of study and practice of occupational therapy. According to the Canadian Model of Occupational Performance (CMOP), an important theoretical model of occupational therapy, refers to the ability to choose, organize

Universidade de São Paulo, Faculdade de Medicina, Instituto de Psiquiatria, Laboratório de Neurociências, São Paulo SP, Brasil.

Correspondence: Paula Villela Nunes, Laboratório de Neurociências (LIM 27), Instituto de Psiquiatria, Hospital das Clínicas da Faculdade de Medicina da USP; Rua Dr Ovídio Pires de Campos, 785; 05403-010 São Paulo SP, Brasil. E-mail: paula@formato.com.br

Conflict of interest: There is no conflict of interest to declare.

Support: Associação Beneficente Alzira Denise Hertzog da Silva (ABADHS)

Received in 27 October 2015; Received in final form 04 April 2016; Approved 18 April 2016. 
and satisfactorily perform meaningful ADL that are culturally defined and age-appropriate for looking after oneself (self-care), contributing to the social and economic fabric of a community (productivity) and enjoying life (leisure) ${ }^{5}$.

In light of this evidence, the use of assessment scales that provide a broader evaluation of ADL is of uOtmost importance. Furthermore, people with MCI can benefit from psychosocial interventions ${ }^{4,6,7}$ but the more specific they are to patients' real needs, the more cost-effective they can be. Commonly used measures for assessing global ADL may not be as sensitive for detecting early functional changes related to MCI as personalized measures based on each individual's difficulties in $\mathrm{ADL}^{8}$. This is because the former measures are usually questionnaires that can overlook some specific difficulties. Consequently, some individual difficulties may not be included in these questionnaires and therefore important data can be lost. Quantitative assessment of functional deficits can indicate early functional changes that are clinically meaningful. Moreover, this method of assessment can be more sensitive for distinguishing healthy elderly from MCI elderly $^{8}$. The Canadian Occupational Performance Measure (COPM) is an instrument that can identify individual difficulties in performing $\mathrm{ADL}^{9,10,11}$.

The COPM is based on the CMOP, a client-centered instrument. It is an individualized measure designed to identify changes in self-perceived occupational performance ${ }^{5}$. Through a semi-structured interview, patients identify their difficulties performing ADL in self-care, productivity, and leisure. There is evidence that the COPM can be effective for measuring changes in the occupational performance difficulties outlined ${ }^{9,10,11}$.

The COPM identifies the activities that individuals want, need or are expected to do, but cannot, or those activities for which interviewees are not satisfied with their current performance. The COPM can be considered an established tool that translates the theory of a client-centered approach into practice ${ }^{12}$. The measure has been applied and validated in individuals with a range of different medical disor$\operatorname{ders}^{9,10,11,12,13,14,15,16,17,18}$, but the literature on the use of the COPM in individuals with MCI remains scant.

Therefore, the primary objective of the present study was to assess self-perceived performance and difficulties in ADL among patients with MCI using the COPM. As a secondary objective, divergent validity and both intra-rater and interrater reliability for the use of COPM in MCI patients were investigated.

\section{METHOD}

\section{Participants}

Fifty-eight elderly adults were included in the study. Participants were volunteers in a prospective annual cohort follow-up on cognitive aging at a university-based psychogeriatric clinic (Institute of Psychiatry, University of Sao Paulo, Brazil), represented by middle-income, community-dwelling individuals from the hospital catchment area. No other interventions occurred during the present study.

Inclusion criteria were: age 65 or older and MCI diagnosis according to the Petersen criteria ${ }^{3}$.

Exclusion criteria were illiteracy, dementia, depression (> 6 points on 21-item Hamilton depression scale - HAM-D) $)^{19}$, visual or hearing disabilities, evidence of previous traumatic brain injury, and other relevant health conditions that could either affect cognition or limit the administration of neuropsychological tests. Laboratory tests performed for all participants included blood count and biochemistry, serum levels of glucose, thyroid hormones, folic acid and vitamin B12, lipid profile and immune tests for syphilis. Neuroimaging scans (magnetic resonance) were performed in all subjects. Detailed information about recruitment and inclusion/exclusion criteria pertaining to this cohort can be found in a previous publication by our group ${ }^{20}$.

Diagnosis of MCI was reached at multidisciplinary consensus meetings, taking into account the available clinical (gathered by psychiatrists and geriatricians), neuropsychological (gathered by neuropsychologists), laboratory, and neuroimaging data, in addition to information provided by a family member. The study protocol comprised patient evaluation using the mini-mental state examination (MMSE) ${ }^{21}$, clock drawing test (CDT), scored according to the Sunderland scale $^{22}$, and verbal fluency test (VFT) (semantic fluency with animal naming). The Hachinski ischemic score ${ }^{23}$ was applied to investigate for evidence of cerebrovascular disease.

This study was approved by the local Ethics Committee and all participants signed an informed consent form.

\section{Procedures}

\section{Reliability study}

The first part of the validation study assessed intra-rater reliability and inter-rater reliability. The sample of $58 \mathrm{MCI}$ patients was randomly subdivided for intra-rater reliability and for inter-rater reliability determination.

To calculate intra-rater reliability, the COPM was administered twice by the same occupational therapist within a mean time interval of 15.8 days $(\mathrm{SD}=6.9)$. To calculate interrater reliability, patients completed the COPM twice on the same day, conducted by two different occupational therapists blinded to the results of the previous COPM. In the reliability analyses, the 5 most important difficulties in ADL and their scores for performance and satisfaction were used in the correlations.

\section{Validation study}

The COPM was then further analyzed by comparing against the self assessment of occupational functioning scale $(\mathrm{SAOF})^{24,25}$ and the role checklist ${ }^{26,27}$. 
The SAOF identifies self-perception of occupational functioning and includes 23 questions related to seven areas of occupational functioning: personal causation, values, interests, roles, habits, skills, and environment.

The role checklist determines an individual's self-perception of participation in occupational roles. First, the instrument assesses participation in 10 major life roles (role incumbency in the past, present, and future): student, worker, volunteer, caregiver, home maintainer, friend, family member, religious participant, hobbyist/amateur, participant in organizations, and other. The second part measures the degree of importance that the individual assigns to each role.

The performance score for ADL problems determined by the COPM was correlated with the total scores of the SAOF and with the number of roles currently performed as assessed by the role checklist.

\section{ADL investigation}

The Brazilian Portuguese version of the $\mathrm{COPM}^{28}$ was used to investigate ADL. It was administered by two occupational therapists, and patients were recruited during a period of 8 consecutive months. The application of COPM took between 10 and 27 minutes and was performed within 6 months of diagnosis of MCI.

Patients were asked to indicate the ADL in which they had difficulties, and to rate the importance of being able to perform each of the reported activities. Each activity is scored from 1 to 10 ( 1 = not important at all; $10=$ extremely important). At the end of the COPM, patients selected the 5 most important activities and rated their performance on a scale from 1 to 10 ( 1 = not able to do it; 10 = able to do it extremely well). The satisfaction of the subject with his/her performance was also rated ( 1 = not satisfied at all; $10=$ extremely satisfied). Total performance and satisfaction scores were calculated by dividing the sum of scores by the number of prioritized problems. Changes in performance and in satisfaction were measured by re-scoring the listed problems after a period of time. Clinically relevant changes were defined as changes of two or more points between scores and re-scores of performance and satisfaction, respectively ${ }^{5}$.

\section{Data analysis}

Statistical procedures were carried out using the Statistical Package for the Social Sciences (SPSS), version 18.0 for Windows, and the significance level was set at $5 \%(p=0.05)$. Normality was tested using the Kolmogorov-Smirnov test. Descriptive data were generated from the sociodemographic and clinical variables. Spearman's correlation test was used for the validity analyses. Reliability was analyzed by intraclass correlation coefficients (ICC) using a one-way random effects model (for the intra-rater study) and a two-way mixed effects model ( for the inter-rater study). ICCs ranging from 0.4 to 0.6 were considered fair, values $>0.6$ good and $>0.75$ excellent $^{29}$.

\section{RESULTS}

The sociodemographic characteristics and clinical variables of the study population are shown in Table 1.

\section{Reliability study}

Twenty-seven patients with MCI participated in the intra-rater reliability study. Of these, 11 patients (40.7\%) identified no problems in both interviews. Twenty-eight MCI patients participated in the inter-rater reliability study. Of these, 3 individuals (10.7\%) identified no problems in both interviews. The correlations of the problems identified, performance and satisfaction are given in Table 2.

\section{Validity study}

Fifty-eight MCI patients were interviewed using the COPM, SAOF and role checklist scales. Significant correlations ( $p=0.42 ; p=0.001)$ were found between mean COPM performance scores for problems in $\mathrm{ADL}$ and total score on the SAOF. Significant correlations $(p=0.31 ; p=0.017)$ were also found between COPM performance scores for ADL problems and the role checklist's number of roles presently performed for each patient.

\section{Study of ADL}

Difficulties in ADL measured by the COPM were present in $74.6 \%$ of this sample of MCI patients. Of the difficulties reported, $41.2 \%$ were related to self-care, $31.4 \%$ to productivity and $27.4 \%$ to leisure. In the self-care category, the five individually-reported most important difficulties were: using the toilet, dressing, bed mobility, climbing stairs, getting in and out of cars, driving a car, using public transportation. These difficulties were reported as being caused by physical difficulties as opposed to cognitive problems, whereas

Table 1. Sociodemographic characteristics and cognitive variables of mild cognitive impairment (MCl) patients.

\begin{tabular}{|c|c|}
\hline & Sample \\
\hline Age (years), mean (SD) & $74.1(5.9)$ \\
\hline Education (years), mean (SD) & $10.0(5.2)$ \\
\hline Females & $70.9 \%$ \\
\hline \multicolumn{2}{|l|}{ Marital status } \\
\hline Married & $52.7 \%$ \\
\hline Divorced/single/widowed & $47.3 \%$ \\
\hline Retired & $81.8 \%$ \\
\hline \multicolumn{2}{|l|}{$\mathrm{MCl}$ diagnosis } \\
\hline Amnestic (single domain and multiple domains) & $78.2 \%$ \\
\hline Non-amnestic (single domain and multiple domains) & $21.8 \%$ \\
\hline MMSE, mean (SD) & $26.9(2.2)$ \\
\hline Verbal fluency, mean (SD) & $14.7(4.7)$ \\
\hline Clock drawing test, mean (SD) & $9.0(3.4)$ \\
\hline HIS, mean (SD) & $1.6(2.3)$ \\
\hline HAMD - mean (SD) & $3.2(4.2)$ \\
\hline
\end{tabular}




\begin{tabular}{lccc} 
& Five most important difficulties in ADL & Performance & Satisfaction \\
\hline Intra-rater $(n=27)$ & $I C C=0.78 ; p<0.001$ & $I C C=0.52 ; p=0.007$ & $I C C=0.13 ; p=0.284$ \\
Inter-rater $(n=28)$ & $I C C=0.69 ; p<0.001$ & $I C C=0.66 ; p<0.001$ & $I C C=0.67 ; p<0.001$ \\
\hline ADL: activities of daily libing; ICC: interclass coefficient correlation. & &
\end{tabular}

using the telephone, paying bills and making purchases were reported as being caused by cognitive deficits. In the productivity category, the five most important difficulties rated were forgetting to buy grocery items and giving messages, preparing meals, taking care of grandchildren reported as being caused by cognitive deficits, plus mopping the floor and washing clothes reported as being caused by physical problems. In the leisure category, the five most important difficulties rated were holding conversations, remembering faces and names, difficulties in reading and keeping up with soap operas, all of which were reported as being caused by cognitive deficits.

It is important to highlight that the COPM is not designed to systematically examine the causes of difficulties in ADL. However, as a semi-structured interview, it provides this information indirectly.

The SAOF revealed that the individuals with MCI had an average occupational functioning score of 44 (maximum score 69 points). The main complaints were related to the ability to perform ADL properly.

The role checklist showed that the major roles performed by the participants were being a family member and a hobbyist/amateur. It is noteworthy that $80 \%$ of the population in this study comprised retired people. Amongst ten different possible roles, the average number of roles performed by the participants was six.

\section{DISCUSSION}

The COPM focuses on identifying the activities each individual needs to do to restore the impaired activities, an important field of occupational therapy. In this study, $74.6 \%$ of MCI patients reported difficulties in complex ADL, as assessed by the COPM. This is in accordance with the recent literature suggesting that some complex ADL are impaired by cognitive deficits in MCI patients ${ }^{1,2}$. The difficulties in ADL reported by the MCI patients assessed involved self-care, productivity and leisure. The average performance score of the problems identified of 5.4 suggests a moderate degree of difficulty performing them. The presence of difficulties in complex ADL, such as planning purchases or paying bills is noteworthy. According to the recommendations from the National Institute on Aging - Alzheimer's Association Workgroups on Diagnostic Guidelines for Alzheimer's Disease $^{2}$, persons with MCI can commonly have mild problems performing complex functional tasks which they were previously able to do, such as paying bills, preparing a meal, or shopping. These individuals may take longer, be less efficient, and make more errors when performing these activities than in the past. Nevertheless, this group generally maintains functional independence in daily life, with minimal aid or assistance. The application of this criterion is challenging, as it requires knowledge about an individual's level of function at the current phase of their life. However, this type of information is also necessary to determine whether a person is demented when there is significant impairment in social or occupational functioning. When cognitive impairment is sufficiently severe to interfere with daily functioning, the patient is diagnosed with $\mathrm{AD}$ dementia. $\mathrm{AD}$ is a slow, progressive disorder, with no fixed events that define its onset, rendering it particularly challenging for clinicians to identify transition points for individual patients. Thus, the point at which an individual transitions from the symptomatic predementia phase to dementia onset is hard to determine. Clinical criteria that can be applied broadly, in any setting, without the need for highly specialized tests and/or procedures are essential.

Therefore, MCI is a syndrome defined by clinical, cognitive, and functional criteria. Sharp demarcations between normal cognition and $\mathrm{MCI}$ and between $\mathrm{MCI}$ and dementia are difficult, and clinical judgment must be used to make these distinctions. There should be evidence of concern over changes in cognition relative to the person's previous level. This concern can stem from the patient, an informant who knows the patient well, or from a skilled clinician observing the patient ${ }^{2}$.

In the present study, the correlation of ADL problems identified in the intra-rater and inter-rater COPM applications were good to excellent. These results provide strong evidence that the COPM can be an effective tool for identifying and prioritizing difficulties that $\mathrm{MCI}$ subjects experience in ADL. These results are similar to findings of a study conducted in elderly with mild $\mathrm{AD}^{13}$ that were able to identify and score problems in ADL using the COPM. In the intrarater reliability part of the present study, good results were found in the correlation of problems in ADL and of performance scores. No correlation was found between satisfaction and performance scores where only mean scores for satisfaction were similar. This might be due to the fact that the satisfaction construct concerns more subjective aspects than the performance construct and therefore the former can change even within a short period of time (about 2 weeks). In other intra-rater studies involving a shorter time interval between 
assessments, better correlations for satisfaction scores were found ${ }^{28,29}$. Accordingly, in the present inter-rater reliability study, both interviews were conducted on the same day where the correlations of the problems, as well as the scores for performance satisfaction, were good. These correlations were stronger than those found in other inter-rater studies $^{16,14}$. The cited studies had an average time interval of 7 days between COPM interviews. This suggests that some items of the COPM may be time sensitive, particularly performance and satisfaction scores.

The validity of the COPM was assessed by comparing against the SAOF and Role Checklist. These scales are derived from different theoretical models and evaluate different dimensions of occupational performance. These aspects may explain the significant but weak-to-moderate correlations found. These results are therefore indicative of divergent validity.

It is noteworthy that some of the ADL problems were reported as being caused not only by cognitive deficits but also physical problems. However, it is important to point out that the COPM is not structured to systematize this data.
Therefore, future studies comparing COPM to specific ADL instruments, as well as gathering this information prospectively, are important for drawing further conclusions.

One limitation of this study is its relatively small sample size. Moreover, although the COPM showed reliable and valid results, the results obtained cannot be extended to groups of people with other types of cognitive impairment such as dementia. Therefore, further studies should be carried out enabling the COPM to be used among patients in different age ranges and with various conditions.

In conclusion the results of the present study suggest that people with MCI can have difficulties performing some complex ADL, as reported in the literature. Furthermore, the MCI patients, despite having cognitive impairment, were able to identify and prioritize their difficulties in ADL. Difficulties in ADL were reported as being caused not only by cognitive deficits but also physical problems.

Moreover, the Brazilian version of the COPM proved valid for examining $\mathrm{ADL}$ and a reliable instrument for identifying and measuring ADL in MCI patients.

\section{References}

1. Pereira FS, Yassuda MS, Oliveira AM, Diniz BS, Radanovic M, Talib LL et al. Profiles of functional deficits in mild cognitive impairment and dementia: benefits from objective measurement. J Int Neuropsychol Soc. 2010;16(2):297-305. doi:10.1017/S1355617709991330

2. Albert MS, DeKosky ST, Dickson D, Dubois B, Feldman HH, Fox NC et al. The diagnosis of mild cognitive impairment due to Alzheimer's disease: recommendations from the National Institute on Aging-Alzheimer's Association workgroups on diagnostic guidelines for Alzheimer's disease. Alzheimers Dement. 2011;7(3):270-9. doi:10.1016/j.jalz.2011.03.008

3. Petersen RC, Smith GE, Waring SC, Ivnik RJ, Tangalos EG, Kokmen E. Mild cognitive impairment: clinical characterization and outcome. Arch Neurol. 1999;56(3):303-8. doi:10.1001/archneur.56.3.303

4. Petersen RC. Mild cognitive impairment. N Engl J Med. 2011;364(23):2227-34. doi:10.1056/NEJMcp0910237

5. Law M, Baptiste S, Carswell A, McColl M, Polatajko H, Pollock N. Canadian occupational performance measure. 4th ed. Ottawa: CAOT Publications; 2005.

6. Li H, Li J, Li N, Li B, Wang P, Zhou T. Cognitive intervention for persons with mild cognitive impairment: A meta-analysis. Ageing Res Rev. 2011;10(2):285-96. doi:10.1016/j.arr.2010.11.003

7. Stott J, Spector A. A review of the effectiveness of memory interventions in mild cognitive impairment $(\mathrm{MCl})$. Int Psychogeriatr. 2011;23(4):526-38. doi:10.1017/S1041610210001973

8. Jefferson AL, Byerly LK, Vanderhill S, Lambe S, Wong S, Ozonoff A et al. Characterization of activities of daily living in individuals with mild cognitive impairment. Am J Geriatr Psychiatry. 2008;16(5):375-83. doi:10.1097/JGP.0b013e318162f197

9. Larsen AE, Carlsson G. Utility of the Canadian Occupational Performance Measure as an admission and outcome measure in interdisciplinary community-based geriatric rehabilitation. Scand J Occup Ther. 2012;19(2):204-13. doi:10.3109/11038128.2011.574151

10. Kang DH, Yoo EY, Chung BI, Jung MY, Chang KY, Jeon HS. The application of client-centred occupational therapy for Korean children with developmental disabilities. Occup Ther Int. 2008;15(4):253-68. doi:10.1002/oti.258
11. Kjeken I, Slatkowsky-Christensen B, Kvien TK, Uhlig T. Norwegian version of the Canadian Occupational Performance Measure in people with hand osteoarthritis: validity, responsiveness, and feasibility. Arthritis Rheum. 2004;51(5):709-15. doi:10.1002/art.20522

12. Dedding C, Cardol M, Eyssen IC, Dekker J, Beelen A. Validity of the Canadian Occupational Performance Measure: a client-centred outcome measurement. Clin Rehabil. 2004;18(6):660-7. doi:10.1191/0269215504cr746oa

13. Clare L, Evans S, Parkinson C, Woods R, Linden D. Goal-setting in cognitive rehabilitation for people with early-stage Alzheimer's disease. Clin Gerontol. 2011;34(3):220-36. doi:10.1080/07317115.2011.555937

14. Eyssen IC, Beelen A, Dedding C, Cardol M, Dekker J. The reproducibility of the Canadian Occupational Performance Measure. Clin Rehabil. 2005;19(8):888-94. doi:10.1191/0269215505cr883oa

15. Sewell L, Singh S. The Canadian occupational performance measure: is it a reliable measure in clients with chronic obstructive airways disease. Br J Occup Ther. 2001;64(6):305-10. doi:10.1177/030802260106400607

16. Cup E, Scholte op Reimer WJ Thijssen M, Kuyk-Minis M. Reliability and validity of the Canadian occupational performance measure in stroke clients. Clin Rehabil. 2003;17:402-9. doi:10.1191/0269215503cr635oa

17. Spadaro A, Lubrano E, Massimiani MP, Gaia P, Perrotta FM, Parsons $W$ et al. Validity, responsiveness and feasibility of an Italian version of the Canadian Occupational Performance Measure for people with ankylosing spondylitis. Clin Exp Rheum. 2010;28(2):215-22.

18. Verkerk GJ, Wolf MJ, Louwers AM, Meester-Delver A, Nollet F. The reproducibility and validity of the Canadian Occupational Performance Measure in parents of children with disabilities. Clin Rehabil. 2006;20(11):980-8. doi:10.1177/0269215506070703

19. Hamilton M. A rating scale for depression.J Neurol Neurosurg Psychiatry. 1960;23(1):56-62. doi:10.1136/jnnp.23.1.56

20. Aprahamian I, Diniz BS, Izbicki R, Radanovic M, Nunes PV, Forlenza OV. Optimizing the CAMCOG test in the screening for mild cognitive impairment and incipient dementia: saving time with relevant domains Int J Geriatr Psychiatry. 2011;26(4):403-8. doi:10.1002/gps.2540 
21. Folstein MF, Folstein SE, McHugh PR. "Mini-mental state": a practical method for grading the cognitive state of patients for the clinician. Psychiatr Res. 1975;12(3):189-98. doi:10.1016/0022-3956(75)90026-6

22. Sunderland T, Hill JL, Mellow AM, Lawlor BA, Gundersheimer $J$, Newhouse PA et al. Clock drawing in Alzheimer's disease: a novel measure of dementia severity. J Am Geriatr Soc. 1989;37(8)725-9. doi:10.1111/j.1532-5415.1989.tb02233.x

23. Hachinski VC, Iliff LD, Zilhka E, Du Boulay GH, McAllister VL, Marshall J et al. Cerebral blood flow in dementia. Arch Neurol 1975;32(9):632-7. doi:10.1001/archneur.1975.00490510088009

24. Baron KB, Curtin C. The self assessment of occupational functioning (SAOF). Chicago: University of Illinois; 1990.

25. Tedesco AS. [Validity and reliability of occupational therapy's instrument: self assessment of occupational functioning (SAOF)]
(Dissertation). São Paulo: Universidade Federal de São Paulo; 2000. Portuguese.

26. Oakley F, Kielhofner G, Barris R, Reichler RK. The role checklist: development and empirical assessment of reliability. Occup Ther J Res. 1986;6(3):157-70. doi:10.1177/153944928600600303

27. Cordeiro JR, Camelier A, Oakley F, Jardim JR. Cross-cultural reproducibility of the Brazilian Portuguese version of the role checklist for persons with chronic obstructive pulmonary disease. Am J Occup Ther. 2007;61(1):33-40. doi:10.5014/ajot.61.1.33

28. Magalhães LC, Magalhães LV, Cardoso AA. Medida canadense de desempenho ocupacional (COPM) - Translation of Canadian Occupational Performance Measure. Belo Horizonte: Editora UFMG; 2009.

29. Fleiss JL. The design and analysis of clinical experiments. New York: Wiley; 1986. 